\title{
Electromyographic gradients during complex visual discrimination learning'
}

AVERY O. VAUGHN and JAMES W. McDANIEL, Department of Physical Medicine and Rehabilitation, University of Colorado School of Medicine, Denver, Colo. 80220

Muscle activity levels during cognitive and motor performances recorded from various electrode placements have, in several studies, been shown to follow monotonically rising gradients throughout the experimental task. A complex match-tosample visual discrimination task employed in this study demonstrated not only a tonic neuromuscular adjustment during performance, but also the occurrence of phasic shifts in activity corresponding to orienting reactions. These phasic responses tend to habituate rapidly with repetitive performance, and are rarely identified in overlearned Ss.

The utilization of muscle-action potentials as a physiological correlate of psychological processes has received frequent attention. Investigators have employed MAP changes as an objective measurement related to "motivation" (Bartoshuk, 1956), "incentive" (Stennett, 1957; Surwillo, 1956), "level of aspiration" (Leshner, 1961; Reuder, 1956), and "attention" (Malmo, 1965). This research suggests that while electromyographic gradients are sensitive to variations in experimental design, they typically reflect a monotonically rising gradient during performance. In reviewing the evidence relating physiological gradients to behavior, Malmo (1965) concludes that the rising gradients do not signify increasing motivation. Rather, EMG gradients are viewed as being required for sustaining attention during a task. Malmo states, "Then, if there is a homeostatic feedback mechanism that keeps activation level relatively constant during a sequence where sustained attention is required, this will involve gradually rising activity of part of the arousal system to overcome the reduced sensitivity of the 'higher' circuits [1965,p. 232]."

MacNeilage (1967) observes that electromyographic gradients during specific trials of a task do not necessarily correspond to overall gradients obtained during the course of the experiment. Information regarding specific EMG changes during performance of a highly controlled learning task would provide additional clarification. Therefore, this experiment examined variations during complex match-to-sample discrimination.
Continuous records of electromyographic variations associated with precisely controlled stimulus events, time intervals, and reinforcements were obtained. METHOD

Seventeen normal adults, ranging in age from 20 to 23 years, participated as Ss. To examine the effects of overlearning, three practiced Ss were included. EMG recordings were made with a Grass Model III-D electroencephalograph. All recordings were from surface disc-type silver electrodes placed approximately $3-4 \mathrm{~cm}$ above the eyes and $45 \mathrm{~cm}$ apart and applied with Grass Type EC-2 Electrode Cream.

A Foringer Visual Test Module was employed for the presentation and control of all stimulus events. This apparatus consists of a $S$ console and a control unit, the console containing a random access slide projector operated photoelectrically by means of code holes punched in the margin of the slides. Slides are mounted so that a sample stimulus (SS) is focused on a press plate centered in the upper console, and the matching stimuli (MS) are focused on a horizontal row of four press plates 2 in. below the upper plate. Independent shutters permit control of the illumination of the upper and lower plates so that SS and MS can be presented simultaneously or successively. The timing of the sample stimulus, interstimulus interval (ISI), matching stim. uli, and intertrial interval (ITI) are all independently variable. Press plates activate the control unit which records correct or incorrect choice, MS selected, and response time.

Constant time intervals were employed as follows: SS duration, $0.5 \mathrm{sec}$; ISI, $3.0 \mathrm{sec}$ and ITI, $3.0 \mathrm{sec}$. Sample and matching stimuli were presented successively, and Ss responded by pressing the plate selected. Correct responses were positively reinforced by a green light on the console, and another sample presented after the ITI. Incorrect responses were negatively reinforced by a red light, and the same array remained until a correct match was made. The Ss were free to make subsequent choices after $3.0 \mathrm{sec}$.

Table 1

Means and Standard Deviations of Maximum Peak Amplitude of Frontalis EMG

\begin{tabular}{|c|c|c|c|c|c|c|c|c|c|c|}
\hline & color 1 - & form 1 & form 1 - & no. 1 & no. 1 . & color 2 & color 2 - & form 2 & form 2 & no. 2 \\
\hline & $+\mathbf{R}$ & $-\mathbf{R}$ & $+\mathbf{R}$ & $-\mathbf{R}$ & $+\mathbf{R}$ & $-\mathbf{R}$ & $+\mathbf{R}$ & $-\mathbf{R}$ & $+\mathbf{R}$ & $-\mathbf{R}$ \\
\hline $\begin{array}{l}\text { Mean } \\
\text { SD }\end{array}$ & $\begin{array}{r}37.06 \\
9.48 \\
\end{array}$ & $\begin{array}{r}31.94 \\
8.45 \\
\end{array}$ & $\begin{array}{l}38.94 \\
10.36 \\
\end{array}$ & $\begin{array}{r}32.82 \\
7.58 \\
\end{array}$ & $\begin{array}{l}42.88 \\
10.01 \\
\end{array}$ & $\begin{array}{r}37.00 \\
8.55 \\
\end{array}$ & $\begin{array}{l}42.47 \\
10.22 \\
\end{array}$ & $\begin{array}{r}35.12 \\
8.81 \\
\end{array}$ & $\begin{array}{l}41.00 \\
10.48 \\
\end{array}$ & $\begin{array}{r}36.71 \\
9.40 \\
\end{array}$ \\
\hline $\begin{array}{l}t(+R /-R) \\
\text { df }=32\end{array}$ & \multicolumn{2}{|c|}{$\begin{array}{l}2.32 \\
\text { NS }\end{array}$} & \multicolumn{2}{|c|}{$\begin{array}{c}2.73 \\
(\mathrm{p}<.05)\end{array}$} & \multicolumn{2}{|c|}{$\begin{array}{c}2.58 \\
(p<.05)\end{array}$} & \multicolumn{2}{|c|}{$\stackrel{3.13}{(p<.05)}$} & \multicolumn{2}{|c|}{$\begin{array}{l}1.75 \\
\text { NS }\end{array}$} \\
\hline
\end{tabular}

While Ss were seated in a semi-reclining chair, control recordsings were made under three conditions: relaxed with eyes closed, viewing a sample stimulus, and finally pressing nonactivated press plates. The experimental task was then initiated with a set of standardized instructions. The task required six sorting or matching operations according to three criteria, i.e., by color, form, or number of geometric designs. Achieving the criterion of 10 consecutive correct matches for one category automatically shifted the task to the next problem until the sequence (color, form, number) had been performed twice. Then a post-test record was obtained.

Variations in frontalis muscle activity were measured in terms of maximum peak amplitude (MPA) during the last second of the 3-sec intertrial interval. These measures were performed following the 10th or final correct response of each criterion, and after Thus, for each $S, 10$ measurements of maximum peak EMG amplitude were obtained. Statistical analyses were based upon these data.

Analysis of variance for MPA measures among 17 Ss revealed no significant differences between the variances associated with the 10 observations $(F=-1.22$, $\mathrm{df}=9 / 16$ ). There was a wide range of individual variability for both correct and incorrect $R s$, but the variability was statistically equivalent for each change in criterion of the experimental problem. Figure 1 represents the characteristic pattern of EMG activity from the frontalis muscle during acquisition of this match-tosample problem. General findings included a higher EMG amplitude associated with correct responding, with attenuation of muscle tension following errors in performance. Furthermore, there was a consistent pattern of progression to this decrease in tension with successive errors, as demonstrated in Fig. 1. The effect persisted until a correct match was achieved.

Figure 2 indicates the mean MPA for each successive criterion change within the experiment. Differences between these means were significant at $\mathrm{F} 1-\mathrm{N} 1$, $\mathrm{N} 1-\mathrm{C} 2$, and $\mathrm{C} 2-\mathrm{F} 2$. Differences between the mean amplitudes on the initial $(\mathrm{C} 1-\mathrm{F} 1)$ and the final change $(\mathrm{F} 2-\mathrm{N} 2)$ in the ensuing error which was unavoidable. 

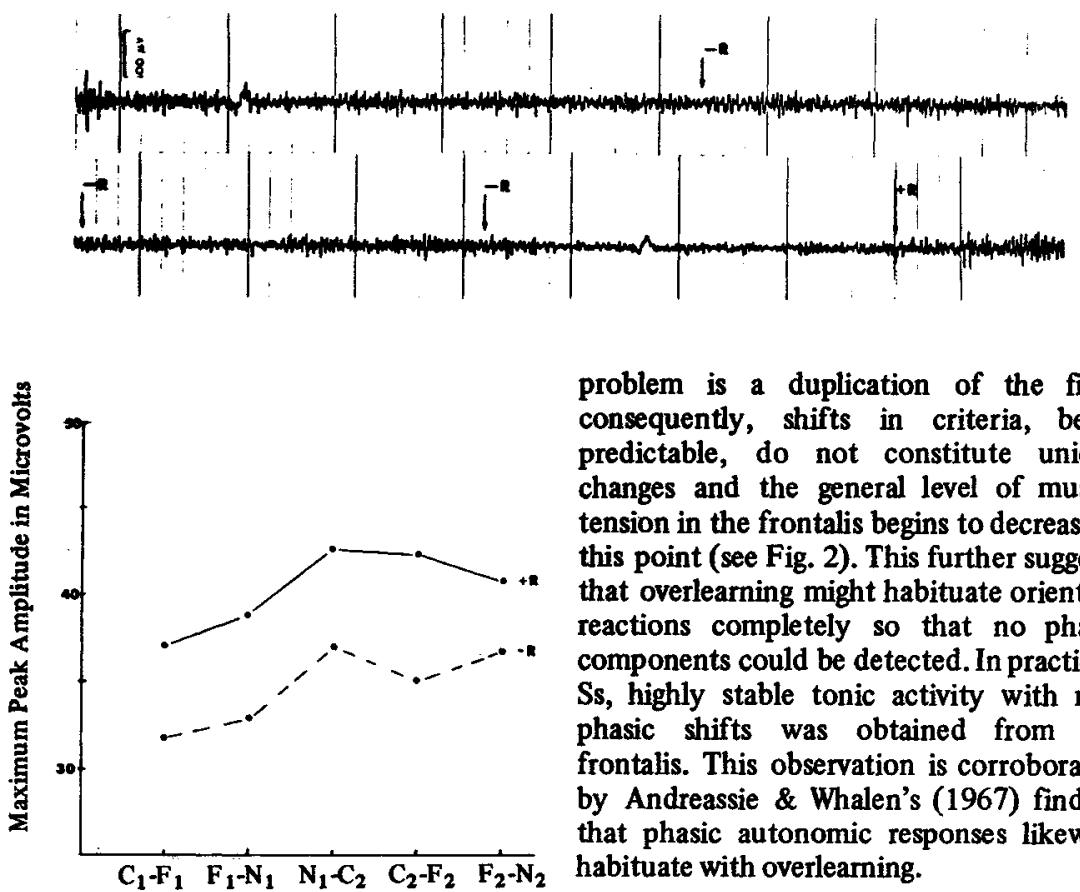

Fig. 2. Maximum peak amplitude of Frontalis EMG during last second of intertrial interval (1) following final correct $R$ and (2) first logical error at each change in criterion. Each point represents the mean amplitude of 17 subjects.

criteria were not statistically significant. Figure 2 also suggests the progressively rising gradient of muscle tension previously reported by several investigators. However, in the present study, the gradient was not monotonic as earlier results have suggested. The lack of significant EMG differences at the first change in criterion is attributed to the absence of an expectancy for change in problem at this stage, making attenuation of muscle tension following the first logical error less consistent in its appearance. Habituation probably accounts for the lack of significance at the last problem shift.

\section{DISCUSSION}

The present findings suggest a tonic neuromuscular orientation by the Ss which may be due, as Malmo (1965) believes, to the need for increasing proprioceptive input to sustain prolonged attention. However, the phasic decrease in frontalis activity when an error is made demonstrates that efferent adjustments in the tonic background are superimposed by the CNS. This adjustment would be consistent with Sokolov's (1963) conception of the orienting reflex, i.e., that phasic activity is dependent upon tonic adjustments and may take the form of either increased or decreased responses against this background. Habituation of phasic orienting reactions explains the decrease in this type of response with the final series of the task. The second part of the match-to-sample problem is a duplication of the first; consequently, shifts in criteria, being predictable, do not constitute unique changes and the general level of muscle tension in the frontalis begins to decrease at this point (see Fig. 2). This further suggests that overlearning might habituate orienting reactions completely so that no phasic components could be detected. In practiced Ss, highly stable tonic activity with rare phasic shifts was obtained from the frontalis. This observation is corroborated by Andreassie \& Whalen's (1967) finding that phasic autonomic responses likewise habituate with overlearning.

\section{REFERENCES}

ANDREASSI, J., \& WHALEN, P. Some physiological correlates of learning and overlearning. Psychophysiology, 1967, 3, 406-413.

BARTOSHUK, A. K. EMG gradients and EEG amplitude during motivated listening. Canadian

\section{JOHN M. TAUB and RALPH J. BERGER, University of California, Santa Cruz, Calif. 95060}

An investigation was undertaken of the possible effects upon performance of sleep in excess of that habitually taken. Twelve Ss worked on 15-min vigilance and calculation tasks on 2 successive days $30 \mathrm{~min}$ after either 8 or $11 \mathrm{~h}$ of nocturnal sleep. The order of sleep length and task presentation was counterbalanced among Ss. Performance on the vigilance task was significantly poorer after $11 \mathrm{~h}$ of sleep than after $8 \mathrm{~h}$ of sleep ( $p<.05)$. Performance on the calculation task was unaffected by the sleep condition. The results indicate that extended sleep can produce decrements in performance similar to those which occur with sleep deprivation.

Although numerous experiments have been conducted examining the relation of performance to sleep deprivation, none have been undertaken to study the possible behavioral effects of sleep in excess of that usually taken. The only investigation in this area was concerned with the physiological
Fig. 1. Progressive decrease in Frontalis EMG activity associated with consecutive errors, and return to previous levels following correct response.

Joumal of Psychology, 1956, 10, 156-164.

LESHNER, S. Effect of aspiration and achievement on muscular tensions. Journal of Experimental Psychology, 1961, 61, 133-137.

MacNEILAGE, P. Changes in electroencephalogram and other physiological measures during serial mental performance. Psychophysiology, 1966, 2,344-353.

MALMO, R. Physiological gradients and behavior. Psychological Bulletin, 1965, 64, 225-234.

REUDER, M. The effect of ego orientation and problem difficulty on muscle action potentials. Journal of Experimental Psychology, 1956,51, 142-148.

SOKOLOV, E. Perception and the conditioned reflex. New York: Pergamon Press, 1963.

STENNETT, $R$. The relationship of performance level to level of arousal. Joumal of Experimental Psychology, 1957, 54, 54-61.

SURWILLO, W. Psychological factors in muscleaction potentials: EMG gradients. Journal of Experimental Psychology, 1956, 52, 263-272.

\section{NOTE}

1. This investigation was supported in part by Research and Training Center Grant RT-10 from the Social and Rehabilitation Service, Department of Health, Education and Welfare, Washington, D.C.

\section{Extended sleep and performance: The Rip Van Winkle effect ${ }^{1}$}

patterns of extended sleep (Verdone, 1968). Although the amount of rapid-eyemovement (REM) sleep increases with time throughout a typical night of $8 \mathrm{~h}$ of sleep (Feinberg, Koresko, \& Heller, 1967; Kales, Wilson, Kales, Jacobson, Paulson, Kollar, \& Walter, 1967), Verdone found that persons sleeping beyond $7 \mathrm{~h}$ or $8 \mathrm{~h}$ had a constant percentage of sleep in this stage, with no evidence that REM sleep "overflowed" to subsequent nights.

Although the question of how much sleep we require has not been systematically investigated, studies on persons living in the Antarctic under conditions of continuous daylight showed them to average $8 \mathrm{~h}$ of sleep each night (Kleitman \& Kleitman, 1953; Lewis \& Masterson, 1957). A recent survey obtained an average duration of sleep of $7 \mathrm{~h}$ $36 \mathrm{~min}$ over ages 20 through 80 , with higher figures reported by the youngest and oldest age groups (Tune, 1968). Taking $8 \mathrm{~h}$ as a normal amount of sleep and on the basis of phenomenological subjective reports of "grogginess" by persons when occasionally sleeping longer than this amount, this study tested the hypothesis that sleep in excess of that habitually taken is deleterious and 